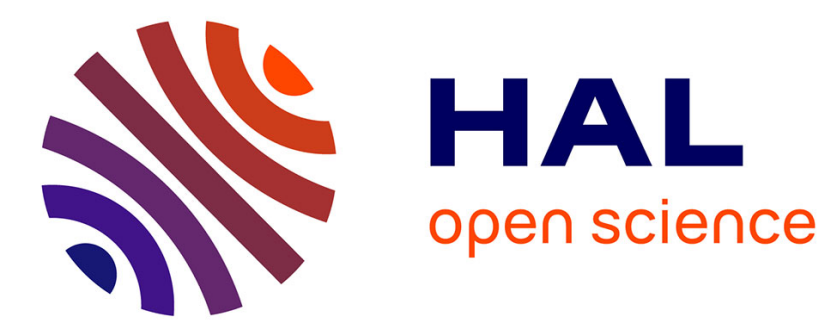

\title{
Liquid anti-solvent recrystallization to enhance dissolution of CRS 74, a new antiretroviral drug
}

Suenia de Paiva Lacerda, Fabienne Espitalier, Valerie Hoffart, Maria-Inês Ré

\section{To cite this version:}

Suenia de Paiva Lacerda, Fabienne Espitalier, Valerie Hoffart, Maria-Inês Ré. Liquid anti-solvent recrystallization to enhance dissolution of CRS 74, a new antiretroviral drug. Drug Development and Industrial Pharmacy, 2015, 41 (11), pp.1910-1920. 10.3109/03639045.2015.1020812 . hal-01611005

\section{HAL Id: hal-01611005 \\ https://hal.science/hal-01611005}

Submitted on 5 Sep 2018

HAL is a multi-disciplinary open access archive for the deposit and dissemination of scientific research documents, whether they are published or not. The documents may come from teaching and research institutions in France or abroad, or from public or private research centers.
L'archive ouverte pluridisciplinaire HAL, est destinée au dépôt et à la diffusion de documents scientifiques de niveau recherche, publiés ou non, émanant des établissements d'enseignement et de recherche français ou étrangers, des laboratoires publics ou privés. 


\title{
Liquid anti-solvent recrystallization to enhance dissolution of CRS 74, a new antiretroviral drug
}

\author{
Suênia de Paiva Lacerda ${ }^{1,2}$, Fabienne Espitalier ${ }^{1}$, Valérie Hoffart ${ }^{2}$, and Maria Inês Ré ${ }^{1}$ \\ ${ }^{1}$ Mines Albi, CNRS, Centre RAPSODEE, Université de Toulouse, Albi, France and "“Conception, Ingénierie et Développement de l'Aliment et du \\ Médicament" (EA CIDAM), UFR Pharmacie, Université d'Auvergne, Clermont-Ferrand, France
}

\section{Abstract}

This study concerns a new compound named CRS 74 which has the property of inhibiting Human Immunodeficiency Virus (HIV) protease, an essential enzyme involved in HIV replication process. It is proved in this study that the original CRS 74 exhibits poor aqueous solubility and a very low dissolution rate, which can influence its bioavailability and clinical response. In an attempt to improve the dissolution rate, CRS 74 was recrystallized by liquid anti-solvent (LAS) crystallization. Ethanol was chosen as solvent and water as the anti-solvent. Recrystallized solids were compared with the original drug crystals in terms of physical and dissolution properties. Recrystallization without additives did not modify the CRS 74 dissolution profile compared to the original drug. CRS 74 was then recrystallized using different additives to optimize the process and formulate physicochemical properties. Steric stabilizer in organic phase ensured size-controlling effect, whereas electrostatic stabilizer in aqueous phase decreased particle agglomeration. Cationic additives avoided drug adsorption onto stainless steel T-mixer. In general, additive improved drug dissolution rate due to improvement of wetting properties by specific interactions between the drug and the additives, and ensured continuous production of CRS 74 by electrostatic repulsion.
\end{abstract}

\section{Keywords}

Additive, antiretroviral drug, bioavailability, dissolution rate, liquid anti-solvent crystallization, solubility

\section{Introduction}

Oral delivery is the most convenient, easy and flexible route of administration for therapeutic drug, especially in case of chronic treatment. Ideally, the biopharmaceutical behavior of the drug, depending on intrinsic physicochemical properties and dosage form of active pharmaceutical ingredient (API), consists of an important fraction of the API being solubilized and non-ionized at the absorption site. Unfortunately, most of the current pipeline drugs are class II or IV in Biopharmaceutical Classification System (BCS), meaning poorly water-soluble with poor permeability for BCS class IV ${ }^{1}$. In such cases, API bioavailability will be limited by the lower of these two parameters, solubility or permeability ${ }^{2}$.

Protease inhibitors which are commonly used worldwide to treat HIV infection are not an exception to this rule. Protease inhibitors have a limited oral bioavailability because of water insolubility and low permeability due to their affinity for the efflux transporter P-glycoprotein ${ }^{3,4}$. Moreover, limited concentration of protease inhibitors reaches systemic circulation because these drugs are substrate for cytochrome P450 3A4 present in

Address for correspondence: Maria Inês Ré, Mines Albi, CNRS, Centre RAPSODEE, Campus Jarlard, Université de Toulouse, F-81013 Albi CT cedex 09, France. Tel: (33) 5 6349 3299. Fax: (33) 5 6349 3025. E-mail: maria-ines.re@mines-albi.fr epithelial cells and hepatocytes ${ }^{5}$. Consequently, high doses are needed to compensate for their first-pass effect and their low oral bioavailability leads to limited and variable drug exposure and clinical implications 6 .

New antiretroviral compounds are continuously synthesized in order to improve treatment efficiency ${ }^{7}$. This is the case of a new ritonavir analogous, $(2 \mathrm{~S}, 3 \mathrm{~S}, 5 \mathrm{~S})-2,-5$-bis-[N-[N-[[N-methyl-N[(2-isopropyl-4-tiazolyl)methyl]amino] carbonyl]vanilyl]amino1,6-diphenyl-3-hydroxyhexane, named CRS 74. This drug presents a promising anti-HIV activity profile (PCT document WO $2005 / 111006$ and US $7763733^{8,9}$ ). It is expected to represent a lower daily dose compared to ritonavir and reduce numerous adverse effects that have limited the use of ritonavir as a single agent at the recommended adult therapeutic dose of $600 \mathrm{mg}$ twicedaily ${ }^{10}$. However, CRS 74, as a typical protease inhibitor, is highly lipophilic and practically insoluble in water. Analogous to ritonavir, CRS 74 is a weak base with a $\mathrm{p} K_{\mathrm{a}}$ close to 3 and similar $\mathrm{pH}$-dependent solubility behavior. Therefore, at acidic $\mathrm{pH}, \mathrm{CRS}$ 74 will be dissolved predominantly in ionized form while at basic $\mathrm{pH}$ - in intestine, for instance, it will be insoluble. Absorption in the stomach will take place step-by-step, while ionization equilibrium is reached. Thus, the dissolution rate has to be as fast as possible to improve bioavailability.

Drug dissolution is a prerequisite for drug absorption and clinical response for almost all drugs given orally. In the case of a poorly water-soluble therapeutic API, it is very challenging to 
modify the molecule or the dissolution environment (solvent and system conditions). Solid forms that have been investigated for drug dissolution enhancement include salts, polymorphs and amorphous, among others. Polymorphs and amorphous formulations can be achieved bt improved solubility but the system is at serious risk of crystallizing to the more thermodynamically stable form, even in the solid state ${ }^{11}$. Such transformations can compromise the performance of the formulation. To save time and resources in product development, relatively simple approaches, such as crystallization, should be tried at the outset.

The liquid anti-solvent (LAS) crystallization process is an attractive method. It requires mild conditions (ambient temperature and atmospheric pressure) with no requirement for expensive equipment. In LAS process, crystallization of solute is achieved by decreasing the solubility of solid in the system. This is done by the addition of a non-solvent component for solute called antisolvent. The introduction of the API solution to the anti-solvent generates high supersaturation that subsequently induces the "birth" of a new solid phase (nucleation), which grows in size, going from dissolved drug in solution to solid in suspension ${ }^{12}$.

The LAS crystallization is well adapted to hydrophobic APIs ${ }^{13,14}$, which are mainly soluble in various water miscible organic solvents. Therefore, objectives of the present work were (i) to determine the physicochemical properties of CRS 74 and (ii) to increase its dissolution rate using the LAS crystallization process with a stainless steel T-mixer.

Firstly, the crystallization process was developed and secondly, the impact of additive addition was evaluated for the ability to produce smaller particle sizes and to modify the surface properties of drug crystals. Microcrystals produced by this LAS crystallization process were characterized in suspension by dynamic light scattering. Physical properties of raw CRS 74 and recrystallized particles were characterized by several techniques: laser diffraction, scanning electron microscopy, thermogravimetric analysis, differential scanning calorimetry, powder X-ray diffraction, sessile drop method, solubility and dissolution tests.

\section{Materials and methods}

\section{Materials}

The active pharmaceutical ingredient (CRS 74, $\mathrm{C}_{46} \mathrm{H}_{66} \mathrm{~N}_{8} \mathrm{O}_{5} \mathrm{~S}_{2}$, (2S, 3S, 5S)-2,-5-bis-[N-[N-[[N-methyl-N-[(2-isopropyl-4-tiazolyl) methyl]amino]carbonyl]vanilyl]amino-1,6-diphenyl-3-hydroxyhexane), with $99 \%$ purity was provided as courtesy by Cristália Ltda (Itapira, SP, Brazil) (Figure 1).

Different additives are used. Sodium dodecyl sulphate (SDS) was purchased from Fluka (Saint Quentin Fallavier, France), Polyoxyethylene sorbitan monooleate (Tween 20), Hydroxypropylmethylcellulose (HPMC-Mw $22 \mathrm{kDa}$ ) and Chitosan of low molecular weight (Mw: $227 \mathrm{kDa}$ ) from SigmaAldrich (Saint Quentin Fallavier, France), and Poloxamer 407 or Pluronic F127 (P-407) from VWR Chemicals (Fontenay sous Bois, France).
Other reagents ethanol (EtOH) (Fluka Analytical, France) and acetonitrile (ACN) were of high-performance liquid chromatography (HPLC) grade (Scharlau Chemie, Spain). They had purity higher than $99 \%$. All products are used as supplied.

\section{LAS crystallization process}

\section{Preparation of CRS 74 microcrystal particles}

A raw (as-received) sample of CRS 74 was recrystallized by a LAS crystallization method using a stainless steel T-mixer was specially manufactured for this study, on the basis of previous works ${ }^{15}$. The experimental apparatus and the T-mixer are shown in Figure 2. The T-mixer (length $17.5 \mathrm{~mm}$ ) had two radial entries of $1 \mathrm{~mm}$ diameter and one outlet tube of $2 \mathrm{~mm}$ diameter. A detailed description of the experimental apparatus is given in our previous work ${ }^{16}$.

Briefly, a certain amount of drug sample was completely dissolved in ethanol at $30 \pm 0.5^{\circ} \mathrm{C}$ at definite concentration (90 mg CRS 74/g solution). After filtration $(0.22 \mu \mathrm{m}$ pore size, VWR, Fontenay sous Bois, France), the drug was recrystallized via the concurrent introduction of the CRS 74 ethanolic solution (flow rate at $11.0 \mathrm{~g} \mathrm{~min}^{-1}$ ) and an anti-solvent stream of water (flow rate at $33.0 \mathrm{~g} \mathrm{~min}^{-1}$ ) in the T-mixer. Gear pumps (mzr7255-hs-f S and mzr-7205-hs-f S, HNP Microsystem, Schwerin, Germany) and a digital mass flow meter/controller (M1X Bronkhorst, Montigny-Lés-Cormeilles, France) were used to ensure minimal flow rate fluctuation and good mixing. After mixing, a definite supersaturation ratio $(\mathrm{S})$ was calculated (Table 1) from the conditions at the entries of the T-mixer by assuming no crystallization. This supersaturation ratio is the maximal supersaturation ratio.

Freshly formed crystals were collected in a vessel under magnetic stirring (speed). To control the mass loss of transfer operations during the process, the amounts of solid and liquid used or produced were strictly controlled in all processing steps (crystallized solids, solution preparations, empty vials and filters). After characterization, the obtained suspension was filtered $(0.45 \mu \mathrm{m}$, Pall 6654 , France) and crystals were dried under vacuum at $50 \pm 1^{\circ} \mathrm{C}$ for $24 \mathrm{~h}$.

\section{Yield calculation}

Theoretical yield is the maximum amount of recrystallized dry crystals that can be created by the given amount of initial mass of raw crystals. The yields of production were calculated as the weight percentage of the crystal powder after drying with respect to the initial total amount of drug used for recrystallization.

\section{Additive addition}

The studied parameters were: (i) phase for incorporation of the additive (organic solution, aqueous solution or both solutions); (ii) additive concentration (above and below $\mathrm{CMC}$ ). The experimental conditions are summarized in Table 1.<smiles>CC(C)c1nc(CN(C)C(=O)N[C@H](C(=O)N[C@H](Cc2ccccc2)C[C@H](O)[C@@H](Cc2ccccc2)NC(=O)[C@@H](NC(=O)N(C)Cc2csc(C(C)C)n2)C(C)C)C(C)C)cs1</smiles>

Figure 1. Chemical structure of CRS 74. 


\section{Microcrystal characterization in suspension}

\section{Size measurement}

Particle sizes and distributions were measured by dynamic light scattering (DLS) using a Zetasizer Nano Zs (Malvern Instruments, Worcestershire, UK), during the crystallization process and at the end of the process. In a first step, at the exit of the T-mixer, the mixed phases were poured into a vessel under gentle magnetic stirring and a sample was immediately submitted to the particle size analysis $\left(t_{0}\right)$. In a second step, to follow the growth of small embryo particles in the crystallization medium, a measurement was done after $150 \mathrm{~s}\left(t_{150}\right)$. To achieve appropriate measurement concentration for analysis, the sample was diluted 5 times using a saturated solution composed of water, ethanol, drug and additive (if required) to prevent dissolution and growth of the particles during measures.

\section{Zeta potential}

The zeta potential $(\zeta)$ was determined in the Zetasizer Nano Zs by measuring the electrophoretic mobility of the particles in suspension. The measurements were performed on diluted sample after size measurements.

\section{Microcrystal characterization in solid state}

\section{Drug content}

CRS 74 microcrystals $(1.5 \mathrm{mg})$ obtained by LAS crystallization were solubilized in approximately $40 \mathrm{~g}$ of ethanol. This solution was then assayed by HPLC (Agilent Chromatograph, Model 1100 series, Agilent, Massy, France) equipped with a UV-Vis detector. The elution was done using a mobile phase consisting of 70:30 acetonitrile:water on HPLC column ProntoSIL 300-5-ODSH

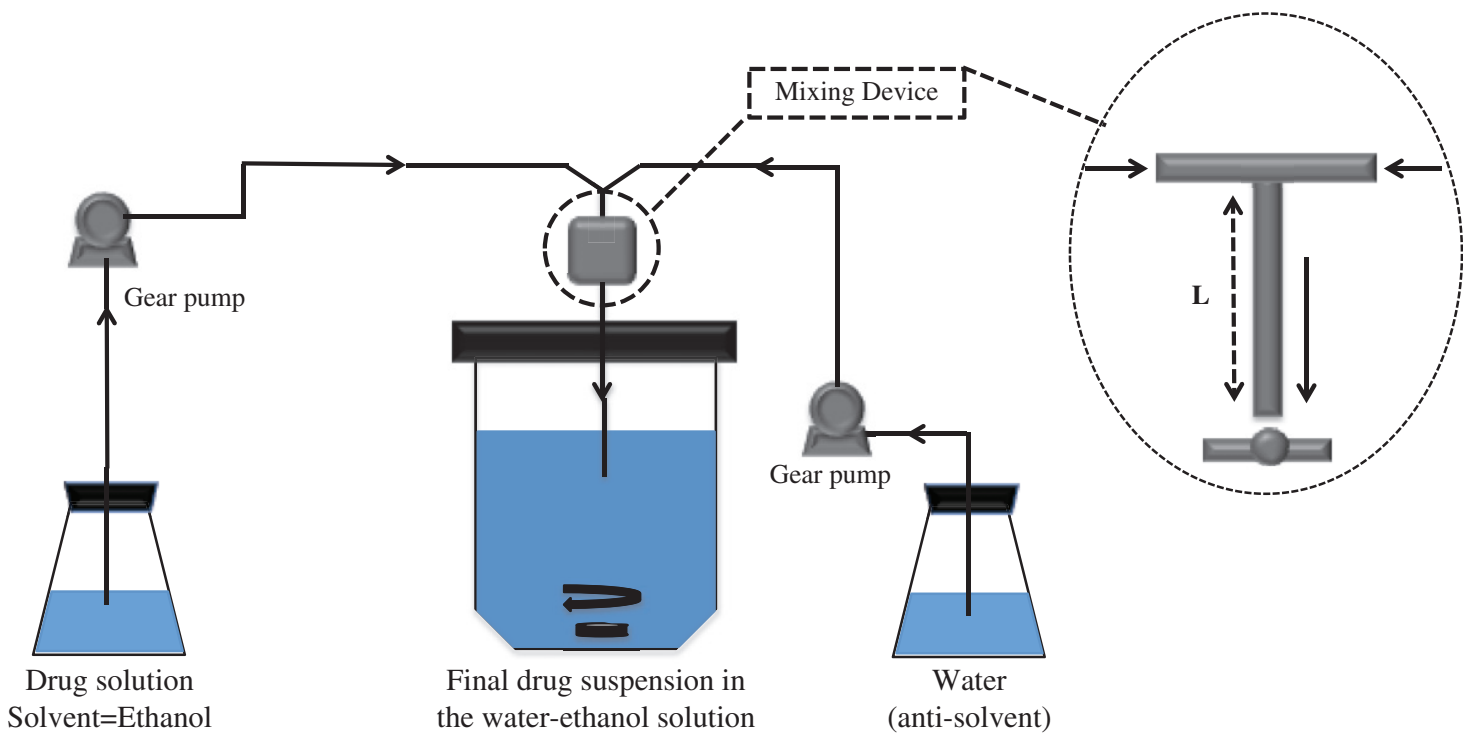

Figure 2. Schematic representation of the experimental apparatus used for the LAS crystallization experiments.

Table 1. Design of experiments conducted for CRS 74 LAS crystallization.

\begin{tabular}{|c|c|c|c|c|c|}
\hline \multirow[b]{2}{*}{ Experiment No } & \multicolumn{2}{|c|}{ Additive $_{\text {Organic phase }}$} & \multicolumn{2}{|c|}{ Additive $_{\text {Aqueous phase }}$} & \multirow[b]{2}{*}{ Supersaturation* } \\
\hline & Type & $\begin{array}{c}\text { Concentration } \\
(\%, \mathrm{w} / \mathrm{w})\end{array}$ & Type & $\begin{array}{c}\text { Concentration } \\
(\%, \mathrm{w} / \mathrm{w})\end{array}$ & \\
\hline 1 & - & - & - & - & 894 \\
\hline 2 & - & - & HPMC & 0.500 & 446 \\
\hline 3 & - & - & Chitosan & 0.500 & $\mathrm{Nd}$ \\
\hline 4 & $\mathrm{P}-407_{\mathrm{C}<\mathrm{CMC}}$ & 0.0003 & - & - & 902 \\
\hline 5 & $\mathrm{P}-407_{\mathrm{C}>\mathrm{CMC}}$ & 0.0200 & - & - & 673 \\
\hline 6 & - & - & Tween $20_{\mathrm{C}<\mathrm{CMC}}$ & 0.008 & 541 \\
\hline 7 & - & - & Tween $20_{\mathrm{C}>\mathrm{CMC}}$ & 0.500 & 399 \\
\hline 8 & - & - & $\mathrm{SDS}_{\mathrm{C}<\mathrm{CMC}}$ & 0.008 & 392 \\
\hline 9 & - & - & $\mathrm{SDS}_{\mathrm{C}>\mathrm{CMC}}$ & 0.500 & 151 \\
\hline 10 & P- $407_{\mathrm{C}<\mathrm{CMC}}$ & 0.0003 & Chitosan & 0.500 & $\mathrm{Nd}$ \\
\hline 11 & $\mathrm{P}-407_{\mathrm{C}>\mathrm{CMC}}$ & 0.0200 & Chitosan & 0.500 & $\mathrm{Nd}$ \\
\hline 12 & P- $407_{\mathrm{C}<\mathrm{CMC}}$ & 0.0003 & $\mathrm{SDS}_{\mathrm{C}>\mathrm{CMC}}$ & 0.500 & 217 \\
\hline 13 & $\mathrm{P}-407_{\mathrm{C}>\mathrm{CMC}}$ & 0.0200 & $\mathrm{SDS}_{\mathrm{C}>\mathrm{CMC}}$ & 0.500 & 194 \\
\hline
\end{tabular}

Nd: not determined due to chitosan interference on HPLC analysis.

*Supersaturation $=\mathrm{C} / \mathrm{C}_{\mathrm{eq}}$, with $\mathrm{C}$, the theoretical drug concentration in the ethanol:water mixture in absence/ presence of additives by assuming no crystallization and $\mathrm{C}_{\mathrm{eq}}$, drug concentration after equilibrium (solubility) in the ethanol:water mixture in the absence/presence of additives at $30^{\circ} \mathrm{C}$. 
( $5 \mu \mathrm{m}, 250 \times 4 \mathrm{~mm} \mathrm{ID)}$, Germany, at a flow rate of $1.0 \mathrm{mLmin}^{-1}$. The amount of dissolved drug was evaluated at $210 \mathrm{~nm}$. The drug retention time was $4.5 \mathrm{~min}$. All experiments were carried out in triplicate. The drug content was calculated as the ratio between the measured drug concentration corresponding to the recrystallized powder and the initial drug concentration corresponding to the raw material.

\section{Residual solvent content}

The residual solvent content (water and ethanol) in dried crystal particles was determined using Infrared balance (LJ16, Mettler Toledo, Viroflay, France) at $100^{\circ} \mathrm{C}$ until a constant weight was achieved. Single experiments were carried out, due the considerable quantities of powder $(500 \mathrm{mg})$ used for this destructive characterization.

\section{Size measurement}

Particle size distributions of dried microcrystals were determined by laser diffraction (DL) using a MasterSizer 3000 laser granulometer (Malvern Instruments, UK). All samples were firstly mixed with Tween $20(50 \mu \mathrm{L})$ and then dispersed in water to achieve the good obscuration.

\section{Scanning electron microscopy analysis (SEM)}

The surface morphology of powder samples was viewed under an environmental scanning electron microscope (XL30 ESEM-FEG, FEI-Philips, Eindhoven, Netherlands) operated at an excitation voltage of $20 \mathrm{kV}$. The powder samples were fixed on an SEM stub using double-sided adhesive tape and sputter coated with platinum at $50 \mathrm{~mA}$ for $6 \mathrm{~min}$ using an ion sputter (SC7640, Polaron, UK) before analysis.

\section{Thermal analysis}

Thermogravimetric analysis (TGA) of raw CRS 74 powder was performed using a thermogravimetric analyzer TG-DSC 111 (Setaram, Lyon, France). The dynamic thermogravimetric curve was recorded under a dynamic nitrogen atmosphere $\left(50 \mathrm{mLmin}^{-1}\right)$ with $5 \mathrm{mg}$ sample packed in aluminum cell. The experiments were run from 20 to $300^{\circ} \mathrm{C}$ at a heating rate of $10^{\circ} \mathrm{C} \mathrm{min}^{-1}$ to determine the temperature range of further DSC analysis and to estimate the degradation temperature.

Differential scanning calorimetric (DSC) measurements were carried out using a DSC-Q200 thermal analyzer (TA Instruments, Guyancourt, France) in a temperature range of 20 to $210^{\circ} \mathrm{C}$ (heating rate $10^{\circ} \mathrm{C} \mathrm{min}^{-1}$ ) under nitrogen atmosphere $\left(50 \mathrm{mLmin}^{-1}\right)$. Samples of raw material and recrystallized CRS 74 (about $3 \mathrm{mg}$ ) were placed in a hermetically closed aluminium pan. The heat of fusion $\left(\Delta H_{\mathrm{f}}\right)$ was calculated using the DSC software (Platinum ${ }^{\mathrm{TM}}$ ).

\section{Powder X-ray diffraction analysis (XRD)}

$\mathrm{X}$-ray diffraction analysis was conducted using an X-ray diffractometer (X'PERT, Philips, Eindhoven, Netherlands) with $\mathrm{CuK} \alpha$ radiation at a scanning rate of $1.228 \theta \mathrm{min}^{-1}$ from 5 to $30^{\circ}$, applying $40 \mathrm{kV}$ at $30 \mathrm{~mA}$ to observe the sample cristallinity.

\section{Contact angle measurement}

Contact angles $(\theta)$ of water on drug substrates were measured by the sessile drop method using a Contact Angle Measuring Instrument (DSA30E, Kruss Instruments, Villebon sur Yvette, France). This method of contact angle measurement uses optics to measure the angle of a drop sitting level on a surface. The powder layer was adopted for the present work as it allows the study of "as is" powder properties. A special cell, conceived for small sample, is filled with the solid. Any surplus of solid is struck off to achieve a plane surface. This method gave reproducible values. A $5 \mu \mathrm{L}$ droplet of the liquid probe (deionized water) was placed on the sample surface and the image of the drop was captured by a CCD digital video camera. All measurements were performed in air under ambient conditions and the reported values are an average of at least three measurements.

\section{Solubility measurement}

Solubility of samples was determined by equilibrating a drug excess in $5 \mathrm{~g}$ of different ethanol:water mixture or $\mathrm{HCl} 0.1 \mathrm{~N}$ $(\mathrm{pH}=1.2)$ at $37 \pm 0.5^{\circ} \mathrm{C}$ in a temperature-controlled bath for $24 \mathrm{~h}$ (equilibrium). The flasks were sealed for the duration of the tests and concentrations were determined after filtration $(0.22 \mu \mathrm{m}$, VWR, Fontenay sous Bois, France). Hydroethanolic solutions were analyzed as described for CRS purity determination. For solubility in $\mathrm{HCl}$, samples were injected into the HPLC system described above and the elution was done using a mobile phase consisting of 50:50 acetonitrile:water (flow rate at $1.0 \mathrm{mLmin}^{-1}$ ) on HPLC column ProntoSIL 120-5 C8 SH $(5 \mu \mathrm{m}, 150 \times 4.0 \mathrm{~mm}$ ID), Germany. The drug retention time was $12 \mathrm{~min}$. Each experiment was carried out in duplicate.

\section{Dissolution method}

Dissolution tests were carried out using sprinkle dissolution method, a USP II dissolution apparatus (DT60 dissolution apparatus, Erweka, Germany). Paddle speed and bath temperature were set at $75 \mathrm{rpm}$ and $37.0 \pm 0.5^{\circ} \mathrm{C}$, respectively. Approximately $30 \mathrm{mg}$ of drug samples, which assured sink conditions $(33 \mu \mathrm{g} /$ gsolution), were placed into vessels containing $900 \mathrm{~mL}$ of $0.1 \mathrm{~N}$ $\mathrm{HCl}$ ( $\mathrm{pH}$ 1.2). Two milliliters samples were withdrawn at specific intervals. The samples were filtered through a $0.22 \mu \mathrm{m}$ filter (Pall 4506, France) before the injection into the HPLC system as described in the solubility measurement part. The cumulative percentage of dissolved drug was plotted against time, in order to obtain the dissolution profile and to calculate the in vitro dissolution data, using the following equation:

$$
\text { Dissolved Drug }(\%)=\frac{A b s_{\text {sample }}}{A b s_{\text {std }}} \operatorname{StdPurity}(\%)
$$

where $A b s_{\text {std }}$ is the absorbance of the standard solution containing the raw CRS $74100 \%$ dissolved, $A b s_{\text {sample }}$ the absorbance of the sample during the dissolution essay as a function of time and StdPurity the purity of the raw material, provided by the supplier.

\section{Results and discussion}

\section{Characterization of the therapeutic candidate CRS 74}

The raw CRS 74 powder (as-received) exhibited a broad particle size distribution $\left(\mathrm{dv}_{90 \%} \mathrm{dv}_{50 \%}\right.$ and $\mathrm{dv}_{10 \%}$ were 515,101 and $4 \mu \mathrm{m}$, respectively) (Figure 3 ). SEM micrograph images showed the presence of agglomerates of several micrometer columnar crystals (Figure 4).

The molecule was characterized by a high melting point $\left(188.6^{\circ} \mathrm{C}\right)$ and a high enthalpy of fusion $(86.6 \mathrm{~J} / \mathrm{g})$ (Table 2$)$. The drug became thermally unstable from $215^{\circ} \mathrm{C}^{16}$. XRD analysis confirmed the crystallinity of CRS 74 and showed peaks at 8.5 , $14,16.9,18.7,19.4$ and 21.3 (Figure 5).

With water as the wetting liquid, original drug crystals exhibited a contact angle of approximately $136^{\circ}$, almost unchanged with time, indicating a poor wettability (Figure 6). Indeed, powder is considered hydrophilic when the contact angle is lower than $90^{\circ}$ and is hydrophobic when this angle is higher ${ }^{17}$. 
The drug solubility in $\mathrm{pH} 1.2$ was low, around $102 \pm 8 \mu \mathrm{g} / \mathrm{g}$ solution at $37^{\circ} \mathrm{C}$. In sink condition, only $20 \%$ of the drug was dissolved within $3 \mathrm{~h}$ in acidic $\mathrm{pH}$ (Figure 7), highlighting a slow dissolution rate related in one hand to large particle size (micrometric range, with broad particle size dispersion) and, in other hand, to very poor water wettability.

\section{LAS crystallization process}

\section{Operating condition optimization}

Solvent:anti-solvent ratio. The solubility of raw CRS 74 in ethanol was estimated to $92.6 \mathrm{mg} / \mathrm{g}$ solution at $30 \pm 0.5^{\circ} \mathrm{C}^{16}$. In order to obtain an indication on the amount of API to be crystallized under experimental conditions, the solubility of CRS 74 in different ethanol:water ratios was determined (Figure 8). A mixing ratio between solvent and anti-solvent of ethanol:water 25:75 (w/w) was fixed with goals (i) to create a high level of supersaturation, (ii) to ensure a high nucleation and (iii) to form fine crystals. Combinations containing high ratio of anti-solvent (water) are favorable for the crystallization process, which induced a high theoretical yield and low drug loss ${ }^{18}$.

Mixer type. Mixing between drug solution and anti-solvent is a critical step to maintain a constant level of supersaturation throughout the crystallizer, to ensure uniform nucleation and to control small embryo particle formation ${ }^{19}$. Static mixer, known (i)

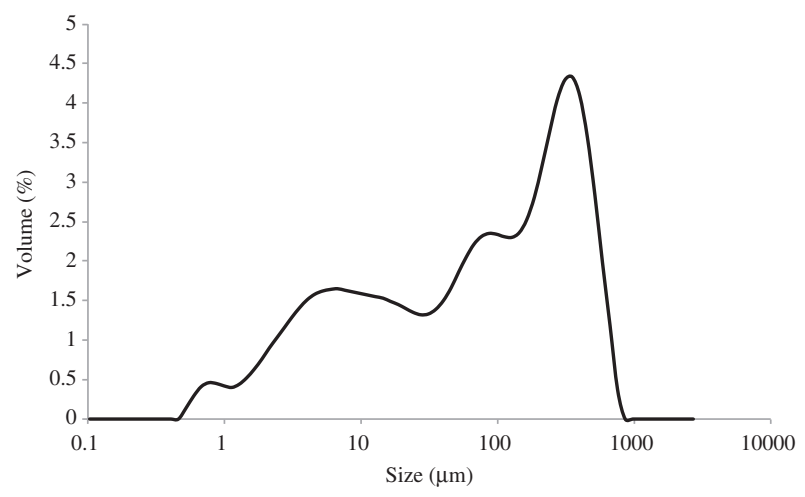

Figure 3. Particle size distribution of raw CRS 74. to intensify the reduced particle size formation by limiting the diffusion length between solvent (containing API) and antisolvent (homogenous supersaturation), (ii) to lead to short residence times and good mixing at low shear rates, was selected ${ }^{20}$. With CRS 74, the turbulent Roughton mixer led to instantaneous agglomeration and process stoppage. These unsuccessful preliminary experiments conducted to the design of a stainless steel T-mixer for this study, on the basis of previous works published in the literature ${ }^{15}$.

Using a stainless steel T-mixer and a mixing ratio between solvent and anti-solvent of ethanol:water 25:75 (w/w), the closure of the mass balance of raw CRS 74 in LAS crystallization process was approximately $81 \%$. A maximal calculated theoretical crystallization yield from experimental solubility data, at the end of experiment, of approximately $99.9 \%$ was expected for this ratio (kinetics not considered) (Figure 8). The difference compared to the maximum theoretical yield was mainly due to the drug loss during washing and drying steps.

LAS recrystallized product characterization. The morphology of elementary crystal observed by SEM is similar to that of raw material (Figure 9). Nevertheless, crystallization process had no impact on columnar CRS 74 crystal morphology. Figure 4 shows that dried LAS recrystallized CRS 74 presented a reduced particle size distribution, compared to the raw product. These results are supported by the less agglomerate powders.

Concerning thermal properties, the melting point, determined by DSC, changed marginally after LAS recrystallization, whereas the fusion enthalpy reduced probably due to the higher surface/ volume ratio exhibited by the LAS recrystallized powder, needing lower energy for melting (Table 2). This reduction could potentially impact the dissolution behavior because crystal energy, correlated with $T_{m \text { (Onset) }}$ (onset melting point) and $\Delta H_{f}$ (enthalpy of fusion), refers to the energy which a compound must overcome to dissolve ${ }^{21}$. Nevertheless, LAS crystallization did not affect the crystalline solid state of CRS 74 (Figure 6).

Table 2. Thermal parameters of CRS 74 after LAS recrystallization.

\begin{tabular}{lcc}
\hline Thermal parameters & Raw & LAS recrystallized* \\
\hline $\mathrm{T}_{\mathrm{m}(\text { Onset })}\left({ }^{\circ} \mathrm{C}\right)$ & 188.6 & 187.8 \\
$\Delta \mathrm{H}_{\mathrm{f}}(\mathrm{J} / \mathrm{g})$ & 86.6 & 79.2 \\
\hline
\end{tabular}

*Without additive.
Figure 4. Particle sizes of the drug powders: raw CRS 74 (-), LAS recrystallized without additive (1), HPMC (2), Chitosan (3), $\mathrm{P}-407 \mathrm{C}<\mathrm{CMC}(4), \mathrm{P}-407 \mathrm{C}>\mathrm{CMC}(5)$, Tween $20 \mathrm{C}<\mathrm{CMC}(6)$, Tween $20 \mathrm{C}>\mathrm{CMC}$ (7), SDS C $<$ CMC (8), SDS C $>$ CMC (9), P-407 C $<$ CMC/chitosan (10), P-407 $\mathrm{C}>\mathrm{CMC} /$ chitosan (11), P-407 C $<\mathrm{CMC} / \mathrm{SDS}$ (12), P-407 C>CMC/SDS (13).

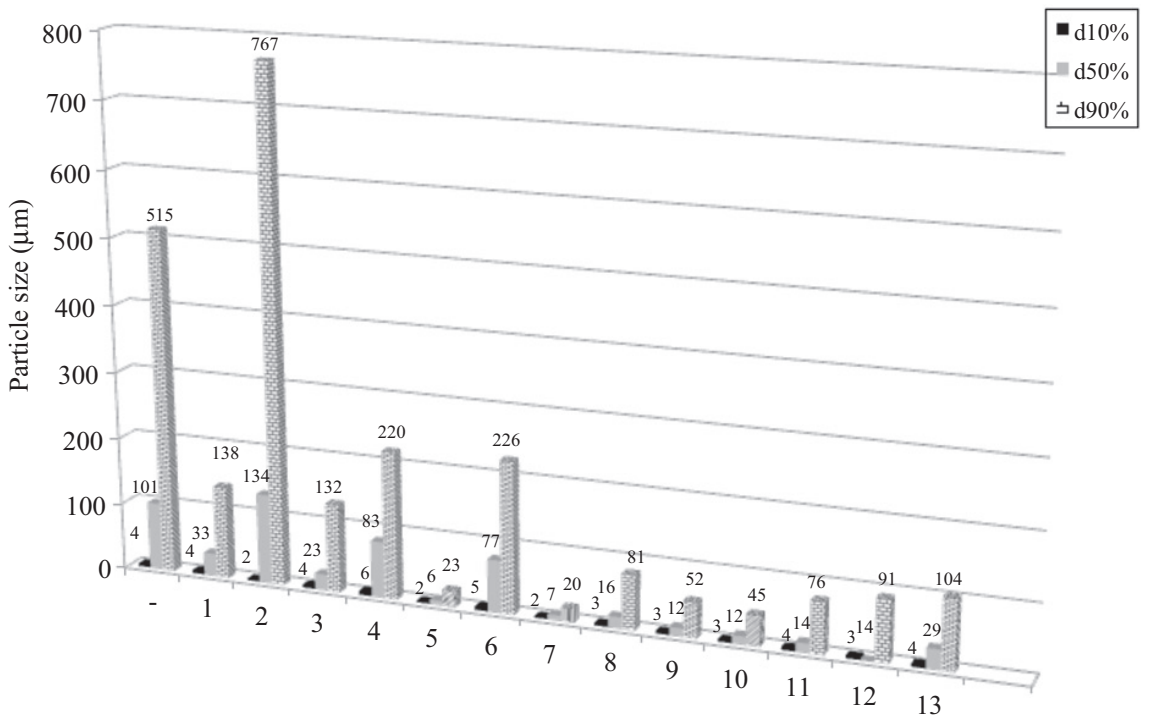


Figure 5. X-ray diffractograms of raw CRS 74 and drug powders recrystallized with and without additives.

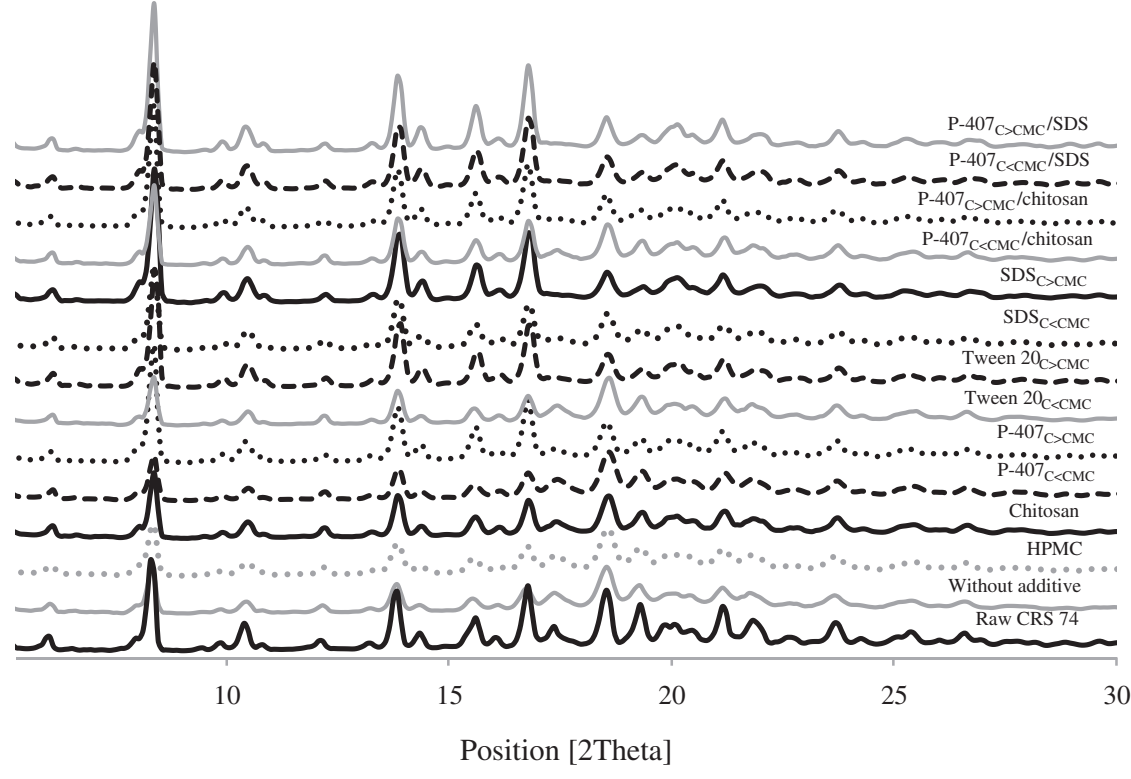

Position [2Theta]

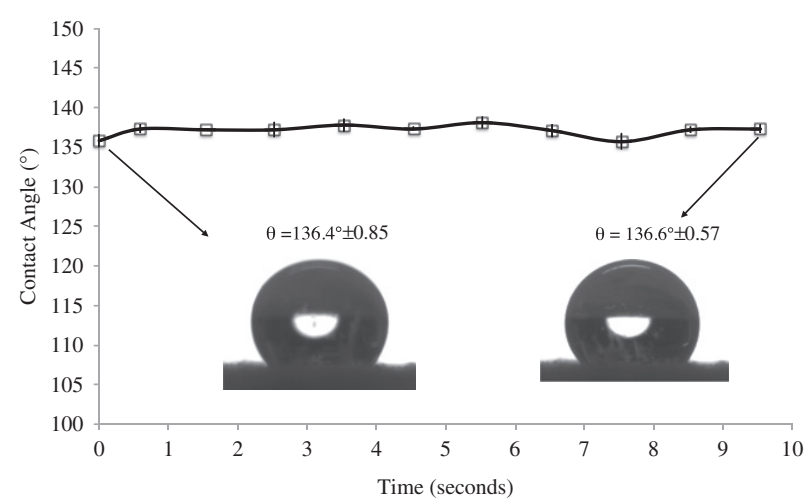

Figure 6. Contact angle $\left({ }^{\circ}\right)$ of water as a function of time for raw CRS 74.

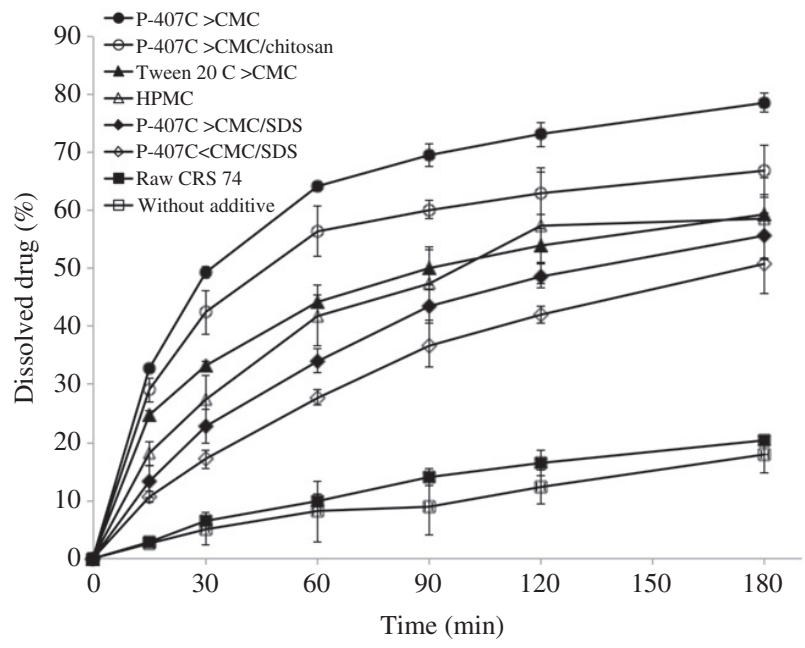

Figure 7. CRS 74 dissolution profiles in $\mathrm{pH} 1.2 \mathrm{HCl}$ at $37^{\circ} \mathrm{C}$ : LAS crystallization effect in presence/absence of different additives $(n=4$, Mean $= \pm 2$ )

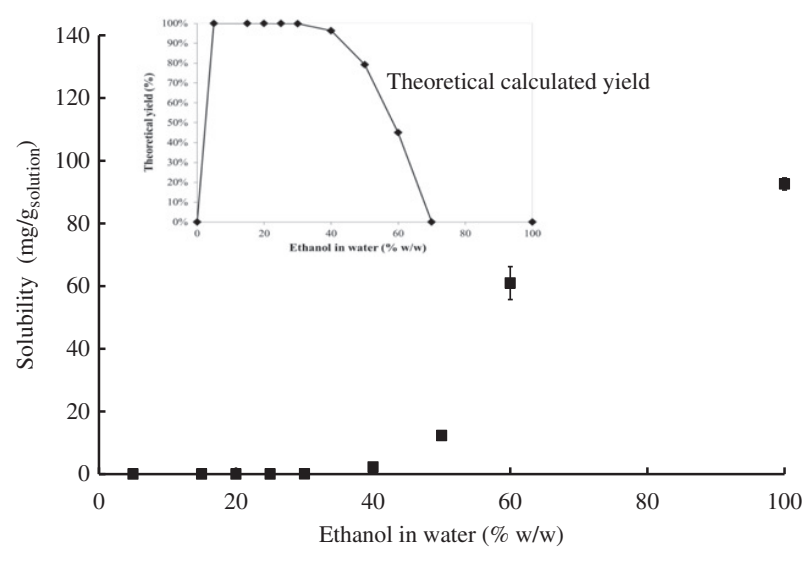

Figure 8. Experimental CRS 74 solubilities in different ethanol-water mixtures at $30 \pm 0.5^{\circ} \mathrm{C}$ and subsequent calculated theoretical crystal yield of CRS 74 after a crystallization at $30^{\circ} \mathrm{C}$.

On the contrary to the expected, the dissolution profile in $\mathrm{pH}$ 1.2 of the obtained hydrophobic crystals $\left(\theta=133.5^{\circ} \pm 1.8\right.$ over the $10 \mathrm{~s}$ period) was not improved (20\% dissolved within $3 \mathrm{~h}$, (Figure 7) despite the drug crystal size reduction. This effect was masked by the crystals agglomeration.

\section{Influence of additive addition}

The feasibility of the LAS crystallization was studied in the presence of different additives in order to produce smaller and/or more hydrophilic particles and to improve dissolution kinetics.

\section{Crystal growth in suspension}

The primary role of stabilizer is to inhibit excessive crystal growth $^{22}$. Classical stabilizers are known to provide sterical stabilization by interaction with the hydrophobic crystal surface ${ }^{23}$. Among different mechanisms of steric stabilization, Tween 20 was chosen for having sufficient affinity to particle surface ${ }^{24}$, whereas HPMC and P-407 were chosen for their ability to form hydrogen bonding ${ }^{25}$. Electrostatic stabilizers such as chitosan and 


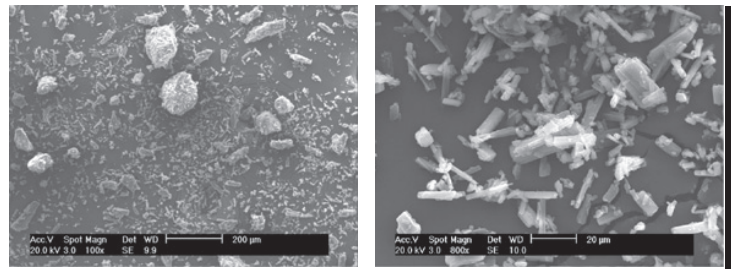

Raw CRS 74

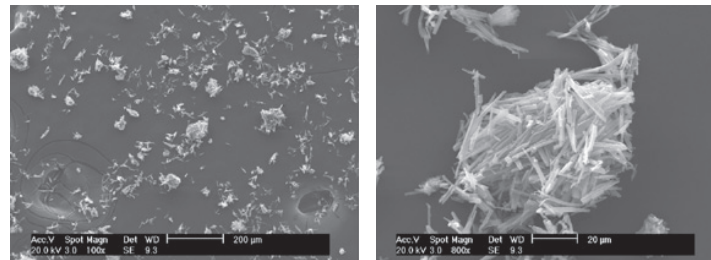

(2) HPMC

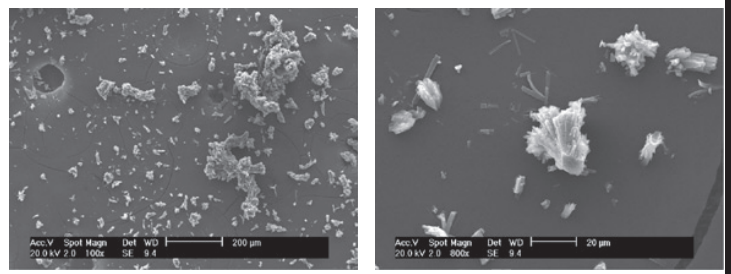

(4) $\mathrm{P}-407_{\mathrm{C}}<\mathrm{CMC}$

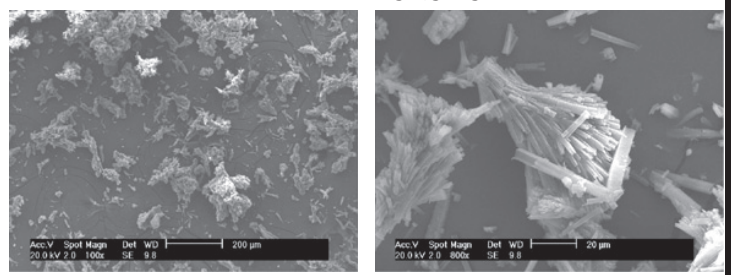

(6) Tween 20 C $<\mathrm{CMC}$

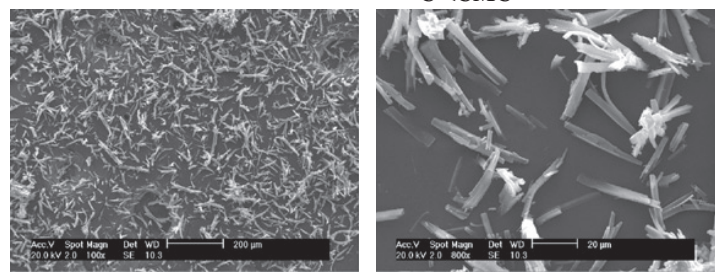

(8) SDS $_{\mathrm{C}<\mathrm{CMC}}$

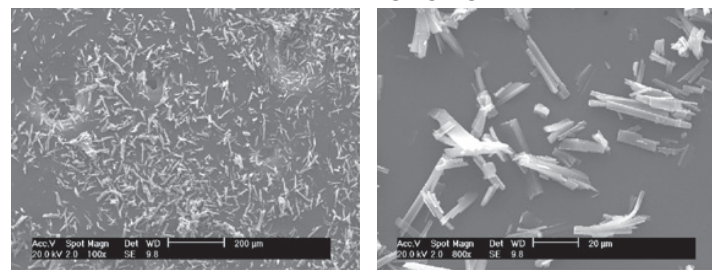

(10) P-407 $\mathrm{C}<\mathrm{CMC} /$ chitosan

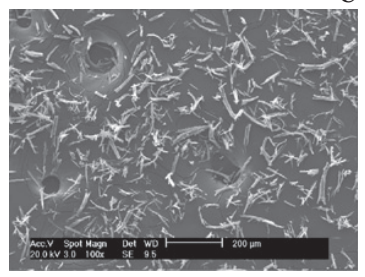

(12) P-407 $\mathrm{C}<\mathrm{CMC} / \mathrm{SDS}$

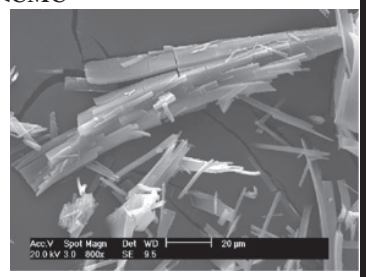

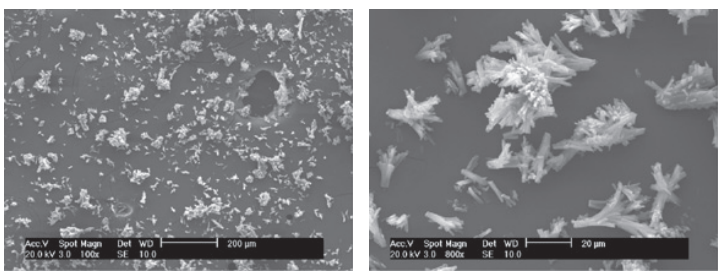

(1) Without additive

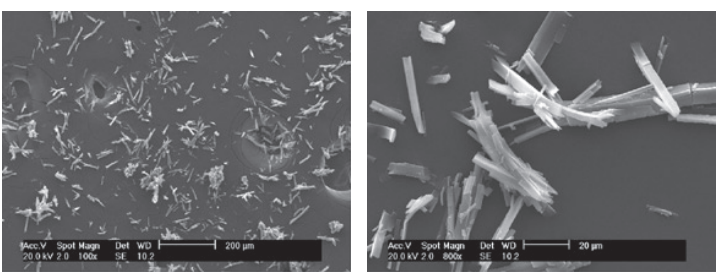

(3) Chitosan

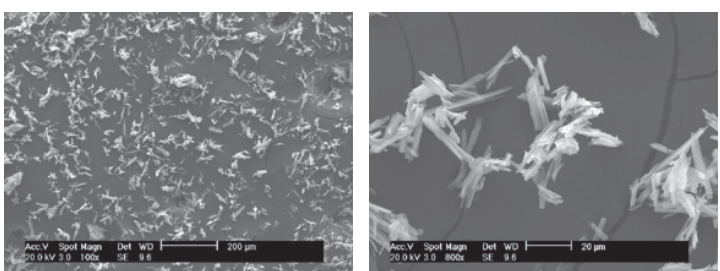

(5) $\mathrm{P}^{-407} \mathrm{C}>\mathrm{CMC}$

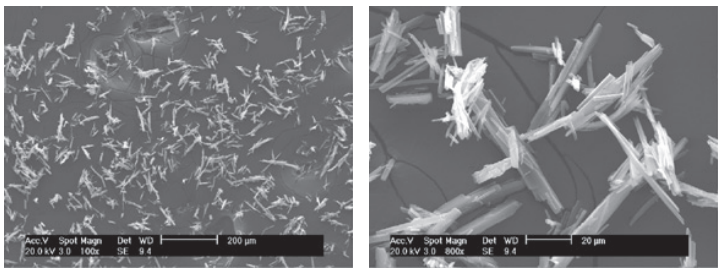

(7) Tween 20 C >CMC

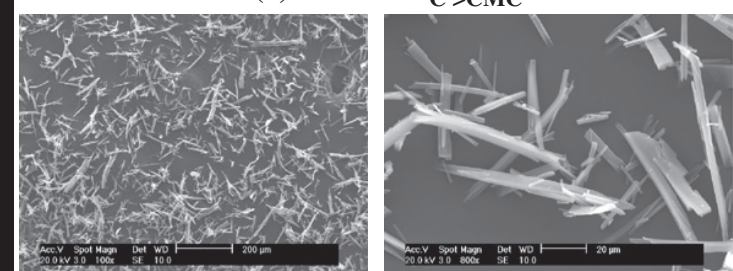

(9) SDS $_{\mathrm{C}>\mathrm{CMC}}$

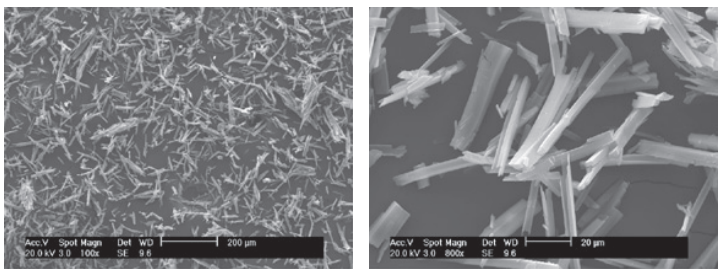

(11) $\mathrm{P}-407 \mathrm{C}<\mathrm{CMC} /$ chitosan
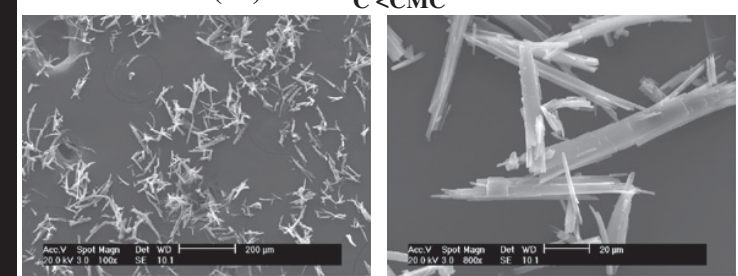

(13) P-407 $\mathrm{C}<\mathrm{CMC} / \mathrm{SDS}$

Figure 9. SEM micrographs of raw CRS 74 and drug powders recrystallized in presence/absence of different additives (right $200 \mu \mathrm{m}-\mathrm{left} 20 \mu \mathrm{m}$ ). 
Table 3. Influence of various additives on characteristics of CRS 74 crystals in suspension properties.

\begin{tabular}{|c|c|c|c|c|c|}
\hline Experiment No. & Additive & $\mathrm{APS}^{*}(\mathrm{~nm}) t_{0}$ & APS* $(n m) t_{150}$ & $\zeta(\mathrm{mV})$ & pHsusp \\
\hline 1 & Without additive & 248 & 417 & $-2.1 \pm 0.3$ & 3.3 \\
\hline 2 & HPMC & 245 & 459 & $-2.4 \pm 0.3$ & 4.9 \\
\hline 3 & Chitosan & 204 & 653 & $+35.2 \pm 1.4$ & 4.4 \\
\hline 4 & $\mathrm{P}-407_{\mathrm{C}<\mathrm{CMC}}$ & 199 & 351 & $-5.4 \pm 0.5$ & 4.4 \\
\hline 5 & $\mathrm{P}-407_{\mathrm{C}>\mathrm{CMC}}$ & 133 & 341 & $-7.5 \pm 0.4$ & 5.7 \\
\hline 6 & Tween $20_{\mathrm{C}}<\mathrm{CMC}$ & 138 & 411 & $-8.6 \pm 1.2$ & 4.5 \\
\hline 7 & Tween $20_{\mathrm{C}>\mathrm{CMC}}$ & 154 & 308 & $-6.7 \pm 1.1$ & 4.6 \\
\hline 8 & $\mathrm{SDS}_{\mathrm{C}<\mathrm{CMC}}$ & 174 & 325 & $-18.5 \pm 0.3$ & 4.4 \\
\hline 9 & $\mathrm{SDS}_{\mathrm{C}>\mathrm{CMC}}$ & 161 & 358 & $-38.9 \pm 2.1$ & 4.4 \\
\hline 10 & P-407 $<<$ CMC $/$ chitosan & 457 & 990 & $+39.4 \pm 3.2$ & 4.6 \\
\hline 11 & $\mathrm{P}-407_{\mathrm{C}>\mathrm{CMC}} /$ chitosan & 596 & 918 & $+16.3 \pm 2.8$ & 4.6 \\
\hline 12 & $\mathrm{P}-407_{\mathrm{C}<\mathrm{CMC}} / \mathrm{SDS}$ & 150 & 368 & $-17.5 \pm 4.7$ & 4.2 \\
\hline 13 & $\mathrm{P}-407_{\mathrm{C}>\mathrm{CMC}} / \mathrm{SDS}$ & 234 & 440 & $-3.9 \pm 0.2$ & 4.3 \\
\hline
\end{tabular}

*Average particle size.

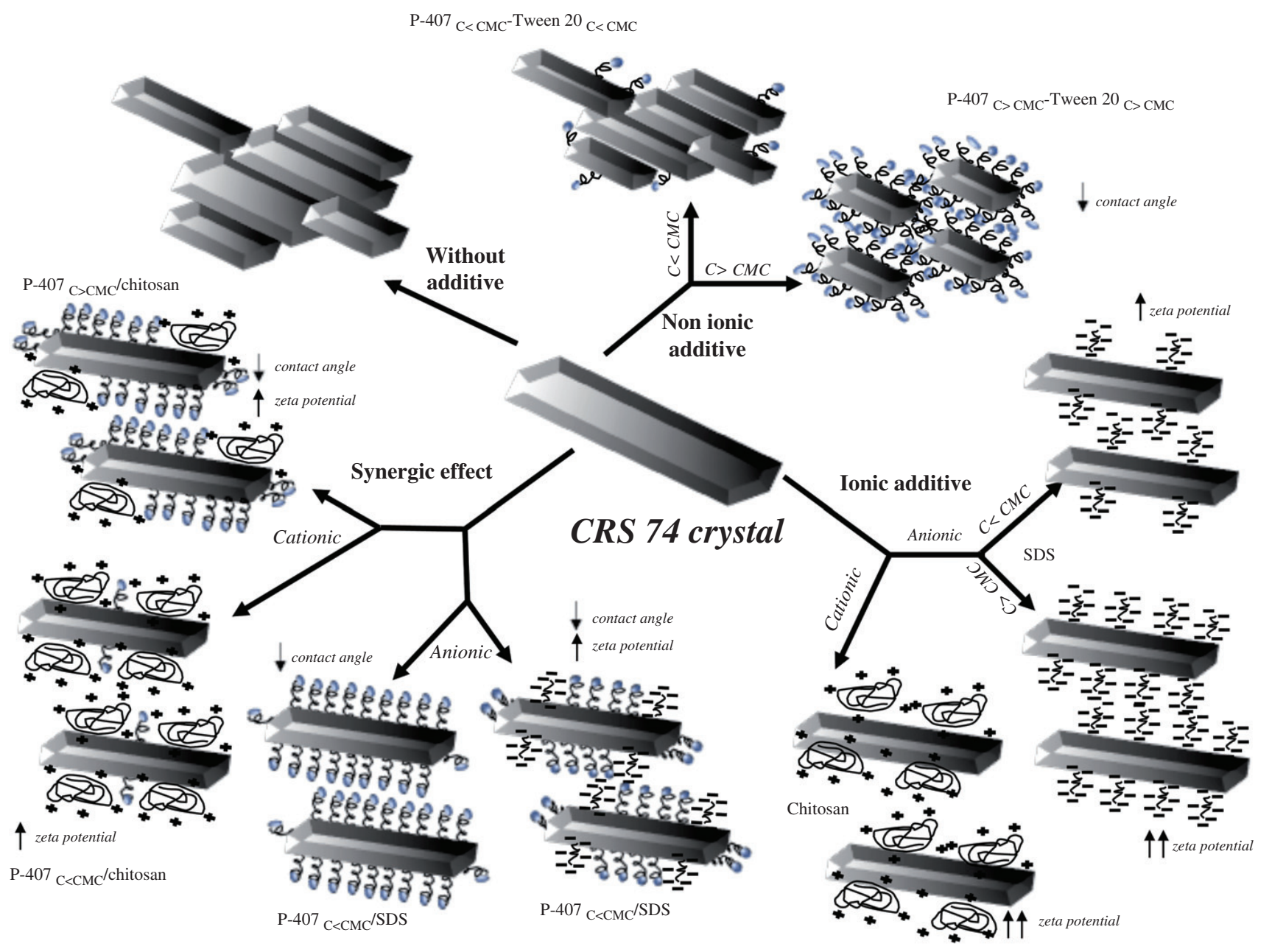

Figure 10. Schematic representation of additives adsorption on CRS 74 crystal surface.

SDS were also tested in order to stabilize crystalline particles by an electrical double layer ${ }^{26}$.

CMC values can be an important parameter to control the crystal growth, subsequently, particle agglomeration: on one hand, high surfactant concentrations can provide a maximum adsorption of additive on crystal surface ${ }^{27}$; on the other hand, when concentration is increased above the $\mathrm{CMC}$, the number of micelles increases leaving the particles unprotected ${ }^{22,23}$. With all stabilizing systems, particles grew quickly and size doubled in $150 \mathrm{~s}$. Moreover, surfactant concentrations below their CMC showed no significant influence on crystal growth (Table 3).

The synergic effect between a pair of stabilizers (mechanisms of steric stabilization and electrostatic repulsion) was also evaluated: steric stabilizer P-407, soluble in organic 
Table 4. Influence of various additives on characteristics of CRS 74 crystals on solid powder state.

\begin{tabular}{|c|c|c|c|c|c|}
\hline Experiment No & Additive & $\theta\left(^{\circ}\right)$ & Purity\% (w/w)* & Solvent $(\%)$ & Yield $(\%)$ \\
\hline 1 & Without additive & $133 \pm 2$ & 98.9 & 0.4 & 79.4 \\
\hline 2 & HPMC & $124 \pm 0$ & 98.6 & 0.9 & 50.2 \\
\hline 3 & Chitosan & $140 \pm 0$ & 100.2 & 0.6 & 64.8 \\
\hline 4 & $\mathrm{P}-407_{\mathrm{C}<\mathrm{CMC}}$ & $133 \pm 3$ & 100.4 & 0.7 & 65.3 \\
\hline 5 & $\mathrm{P}-407_{\mathrm{C}>\mathrm{CMC}}$ & $85 \pm 1$ & 96.1 & 0.6 & 70.9 \\
\hline 6 & Tween $20_{\mathrm{C}}<\mathrm{CMC}$ & $136 \pm 2$ & 101.5 & 0.6 & 47.1 \\
\hline 7 & Tween $20_{\mathrm{C}>\mathrm{CMC}}$ & $100 \pm 0$ & 98.2 & 0.6 & 86.8 \\
\hline 8 & $\mathrm{SDS}_{\mathrm{C}<\mathrm{CMC}}$ & $135 \pm 1$ & 99.1 & 0.6 & 76.6 \\
\hline 9 & $\mathrm{SDS}_{\mathrm{C}>\mathrm{CMC}}$ & $136 \pm 2$ & 100.5 & 0.7 & 75.6 \\
\hline 10 & $\mathrm{P}-407_{\mathrm{C}<\mathrm{CMC}} /$ chitosan & $141 \pm 3$ & 98.9 & 1.5 & 76.4 \\
\hline 11 & $\mathrm{P}-407_{\mathrm{C}>\mathrm{CMC}} /$ chitosan & $94 \pm 4$ & 98.8 & 0.9 & 83.7 \\
\hline 12 & $\mathrm{P}-407_{\mathrm{C}<\mathrm{CMC}} / \mathrm{SDS}$ & $107 \pm 1$ & 99.9 & 0.6 & 72.7 \\
\hline 13 & $\mathrm{P}-407_{\mathrm{C}>\mathrm{CMC}} / \mathrm{SDS}$ & $74 \pm 5$ & 99.6 & 0.9 & 87.8 \\
\hline
\end{tabular}

*Standard deviation not significant.

Table 5. Percentage of drug dissolved within the first $30 \mathrm{~min}$ in $\mathrm{pH} 1.2$ $(n=4$, Mean $= \pm 2)$

\begin{tabular}{rcr}
\hline Experiment No & Additive & $\begin{array}{c}\text { Percentage of drug } \\
\text { dissolved in } 30 \mathrm{~min}\end{array}$ \\
\hline- & Raw CRS 74 & $6.58 \pm 0.30$ \\
1 & Without additive & $5.12 \pm 2.77$ \\
12 & $\mathrm{P}-407_{\mathrm{C}<\mathrm{CMC} / \mathrm{SDS}}$ & $17.12 \pm 1.64$ \\
13 & $\mathrm{P}-407_{\mathrm{C}>\mathrm{CMC}} / \mathrm{SDS}$ & $22.77 \pm 2.99$ \\
2 & $\mathrm{HPMC}$ & $23.36 \pm 4.31$ \\
7 & Tween $20_{\mathrm{C}>\mathrm{CMC}}$ & $33.16 \pm 0.74$ \\
11 & $\mathrm{P}-407_{\mathrm{C}>\mathrm{CMC}} /$ chitosan & $42.43 \pm 3.77$ \\
5 & $\mathrm{P}-407_{\mathrm{C}>\mathrm{CMC}}$ & $49.32 \pm 0.94$ \\
\hline
\end{tabular}

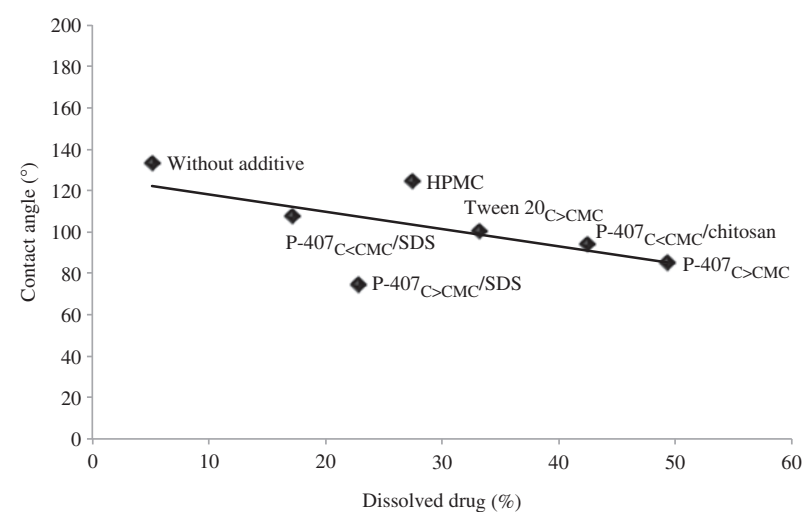

Figure 11. Drug dissolution correlation to contact angle value $\left(r^{2}>0.9\right.$ without HPMC and $\left.\mathrm{P}-407_{\mathrm{C}>\mathrm{CMC}} / \mathrm{SDS}\right)$ at $30 \mathrm{~min}$ and at $37^{\circ} \mathrm{C}$.

phase, was chosen and associated with SDS or chitosan in aqueous phase.

Crystals generated in presence of P-407/SDS were discrete with a size of approx. $200 \mathrm{~nm}$. P-407/chitosan led to bigger crystals, but always in nanometric range of size. Crystal size was again of two fold in $150 \mathrm{~s}$ (Table 3).

\section{Zeta potential value}

Table 3 also showed the changes on zeta potential of particles in the presence of additives. When the crystals were synthesized without additive, the surface charge was negligible $(-2.1 \mathrm{mV})$. Values remained below $|9| \mathrm{mV}$ with HPMC, P-407 and Tween 20. Zeta potential absolute value increased consistently with SDS or chitosan, indicating adsorption of their charged parts onto the crystal surface ${ }^{28,29}$. With increasing SDS concentration, electronegativity increased indicating an increase of charge density at the crystal surface. Generally, suspensions with zeta potential above $|30| \mathrm{mV}$ are physically stable ${ }^{30,31}$, therefore electrostatic additive can play a decisive role in controlling aggregation of freshly formed crystal drug.

Concerning synergic effect, $\mathrm{P}-407_{\mathrm{C}<\mathrm{CMC}}$ associated to chitosan also led to a system predicted as stable, due to its high zeta potential value. From zeta potential observation, P- $407_{\mathrm{C}<\mathrm{CMC}}$ seemed to not disturb chitosan repartition around the crystal surface $(\zeta=+39 \pm 3 \mathrm{mV}$ versus $+35 \pm 1 \mathrm{mV})$. This can be related to the high molecular weight of chitosan and consequently his high coverage capacity ${ }^{32}$. Nevertheless, P-407 $>$ CMC seemed to limit the number of chitosan molecules adsorbed on crystal surface by zeta potential value reduction $(\zeta=+16 \pm 3 \mathrm{mV})$, as illustrated in Figure 10.

$\mathrm{P}-407_{\mathrm{C}<\mathrm{CMC}}$ combined with SDS probably disturbed the SDS adsorption on crystal surface $(\zeta=-17 \pm 4 \mathrm{mV}$ versus $-38 \pm 2 \mathrm{mV}$ ) (Table 3 ). Moreover, zeta potential absolute value decreased even more when $\mathrm{P}-407_{\mathrm{C}>\mathrm{CMC}}$ was present, indicating the adsorption of the steric stabilizers on particle surface ${ }^{33}$. SDS was probably in competition with P-407 during surface crystal coverage, the adsorption rate of P-407 was likely to be faster with stronger interaction onto crystal surface (Figure 10).

Drug content, residual solvent and yield

For all formulations, CRS 74 contents in microcrystal were above 96\%. All solvents were entirely removed through drying step (residual solvent below 1\%) (Table 4).

Yield (final product) of 50 to $87 \%$ was obtained after LAS crystallization. These values determined a great extent of the process compared with other systems studied ${ }^{34}$.

\section{Dried powder morphology and particle size distribution}

Additives had no impact on columnar crystal shape. Comparison between SEM observations and particle size distribution obtained by laser granulometry indicated that high $\mathrm{dv}_{90 \%}$ value corresponded to agglomeration of small particles (Figures 4 and 9). Addition of almost all additives led to a reduction of particle agglomeration. Contrarily, with HPMC, clusters of primary particles formed agglomerates. In this case, the high viscosity of the HPMC/anti-solvent solution could prevent drug diffusion from organic solution resulting in non-uniform supersaturation and agglomeration ${ }^{35}$.

Based on SEM observations, SDS, the best anti-agglomeration stabilizer was efficient already below the CMC when high concentrations of P-407 or Tween 20 were required to avoid 
agglomeration. After washing and drying steps, additive can remain on crystal surface preventing particle aggregation. Consequently, despite a negligible zeta potential value $(<|9| \mathrm{mV})$, particles were efficiently stabilized by a surface coverage of the diffuse layer with uncharged stabilizer. In such cases, zeta potential measurement cannot be, by itself, a sufficient method to predict additive effectiveness.

Besides an anti-agglomeration effect, $\mathrm{P}-407_{\mathrm{C}>\mathrm{CMC}}$ seemed to be the more efficient size-controlling stabilizer (Figure 4). Indeed, this block co-polymer surfactant, containing ethylene glycol and propylene glycol, has multiple hydrophobic moieties able to adsorb onto drug hydrophobic particle surface and two hydrophilic blocks, which provide an effective steric barrier against not only agglomeration but also crystal growth ${ }^{36,37}$.

Tween $20_{\mathrm{C}>\mathrm{CMC}}$ has also a size stabilizing effect as small particles were observed (Figure 4). This additive probably occupied, during LAS crystallization, a high number of adsorption sites on the surface of freshly formed CRS 74 microcrystals. As already described for other drugs such as folic acid, this interaction can inhibit subsequent growth by limitation the drug incorporation from solution into crystal lattices ${ }^{24}$.

On the contrary, SDS and chitosan seemed less efficient to control crystal size. They were probably not homogeneously distributed onto all crystal face due to specific interaction at the crystal/liquid interface ${ }^{38}$ (Figure 10). As a result, crystals grown in the presence of SDS or chitosan were elongated plates ${ }^{39}$.

\section{Powder XRD analysis}

Crystals generated in presence of additives retained the same crystalline polymorphic form (Figure 5). However, slight modifications of peak intensities suggested change only in crysta habit $^{37}$.

\section{Wettability}

The wettability of CRS 74 was modified by some additives (Table 4). Contact angle value decreased drastically with high concentration of $\mathrm{P}-407_{\mathrm{C}>\mathrm{CMC}}$ and Tween $20_{\mathrm{C}>\mathrm{CMC}}$ and in a lower extent with HPMC. Interestingly, in the presence of $\mathrm{P}-407_{\mathrm{C}>\mathrm{CMC}}$ $\left(\theta=85^{\circ}\right)$, hydrophobic CRS 74 exhibited hydrophilic properties. This remarkable effect and the reduction of particle size distribution reinforced the hypothesis that P-407 and Tween 20 remained certainly attached, after washing and drying step, to the hydrophobic drug particle surface lowering the interfacial tension, aggregation and crystal growth. Contact angle was also noteworthy decreased by additives association.

\section{Influence of additives on solubility and dissolution rate}

Only formulations, which lowered contact angle value, were investigated further. $\mathrm{HCl} 0.1 \mathrm{~N}$ pH 1.2 was chosen as a discriminatory dissolution medium, due to drug pKa value close to 3 and $\mathrm{pH}$-dependent solubility behavior.

Drug solubility was not influenced either by processing or by additive addition (date not shown) but additive addition led to a faster dissolution rate (Table 5 and Figure 7). At $3 \mathrm{~h}$, the percentage of drug dissolved increased depending on the additive.

In a general manner, drug dissolution correlated well with contact angle, except for HPMC and $\mathrm{P}-407_{\mathrm{C}>\mathrm{CMC}} / \mathrm{SDS}$ (Figure 11). Wettability is indeed one of the most important factors dominating dissolution of drug crystals. Contact angle can be potentially used to screen formulation of additives for LAS recrystallization of CRS 74. Best results were obtained with P-407 $>$ CMC associated or not with chitosan: the percentage of drug dissolved drug dissolution was enhanced from 5-6\% to almost $50 \%$ in $30 \mathrm{~min}$ (Table 5).

\section{Benefit of additives for continuous process}

A continuous process of production through the stainless steel T-mixer was possible only with chitosan into the aqueous phase. With all other formulations, LAS process using stainless mixer proved to be quite laborious due to the rapid growth and particle agglomeration, which precluded the realization of essays over time $^{16}$ (data not shown). Indeed, stainless steel can present different surface charge properties as a function of $\mathrm{pH}$. The material surface is positively charged over the specific operating $\mathrm{pH}$ range of 3 to $5^{40}$. Because of this, the surface charge of stainless steel allows it to act as an adsorption sites for CRS 74, when not in the presence of positive charges of chitosan.

The association of $\mathrm{P}-407_{\mathrm{C}>\mathrm{CMC}}$ in the organic phase and chitosan in the aqueous phase was the best formulation, improving CRS 74 dissolution profile and solving blockage problem ensuring a continuous process of CRS 74 production by electrostatic repulsion (Experiment 11, Table 3).

\section{Conclusion}

CRS 74, a new protease inhibitor, with high biological activity but low oral bioavailability, has a very low aqueous solubility and dissolution rate. The LAS recrystallization process was a simple and effective approach to produce CRS 74 microcrystals with reduced particle size, however with no faster dissolution rate due to an agglomerate state of the dried recrystallized powders. Additive addition during the LAS process improved the drug dissolution rate, due to the increase of wetting properties attributable by specific interactions between the drug surface and the additive. Introduction of steric stabilizer in organic phase ensured an efficient size controlling effect, whereas electrostatic stabilizer in aqueous phase decreased particle agglomeration. Positive superficial charges around newly generated particles were necessary to avoid drug adsorption onto stainless steel $\mathrm{T}$ mixer. Consequently, synergic effect of P-407 and chitosan led to continuous process and improvement of drug dissolution 10 times in $30 \mathrm{~min}$. This formulation will be further characterized in vivo after oral administration to rats. Lastly, the LAS process leads to suspensions of CRS 74 microcrystals in ethanol/water, which were transformed in dry crystals using vacuum filtration and oven drying. Instead of oven drying, in order to prepare solid dosage forms out of stable dry CRS 74 crystals, spray drying could be used as a continuous downstream processing following the LAS process.

\section{Acknowledgements}

The authors would like to thank Cristália Ltda (Itapira, SP, Brazil) for providing the drug CRS 74 .

\section{Declaration of interest}

The authors report no conflicts of interest. The authors alone are responsible for the content and writing of the paper.

\section{References}

1. Lipp R. The Innovator pipeline: bioavailability challenges and advanced oral drug delivery opportunities. Am Pharm Rev 2013;16: 14-16.

2. Dahan A, Miller JM, Amidon GL. Prediction of solubility and permeability class membership: provisional BCS classification of the world's top oral drugs. AAPS J 2009;11:740-6.

3. Woodahl EL, Yang Z, Bui T, et al. MDR1 G1199A polymorphism alters permeability of HIV protease inhibitors across P-glycoproteinexpressing epithelial cells. AIDS 2005;19:1617-25.

4. Holmstock N, Annaert P, Augustijns P. Boosting of HIV protease inhibitors by ritonavir in the intestine: the relative role of cytochrome P450 and P-glycoprotein inhibition based on Caco-2 
monolayers versus in situ intestinal perfusion in mice. Drug Metab Dispos 2012;40:1473-77.

5. Barry M, Mulcahy F, Merry C, et al. Pharmacokinetics and potential interactions amongst antiretroviral agents used to treat patients with HIV infection. Clin Pharmacokinet 1999;36:289-304.

6. Pulido F, Matarranz M, Rodríguez-Rivera V, et al. Boosted protease inhibitor monotherapy: what have we learnt after seven years of research? AIDS Rev 2010;12:127-34.

7. De Clercq E. Dancing with chemical formulae of antivirals: a panoramic view (Part 2). Biochem Pharmacol 2013;86:1397-410.

8. Bockelmann MA, Rosatto SS, Fuzeto CR, et al. Ritonavir analogous compound useful as retroviral protease inhibitor, preparation of the ritonavir analogous compound and pharmaceutical composition for the ritonavir analogous compound. European Patent, WO 2005/ 1110062005.

9. Bockelmann MA, Rosatto SS, Fuzeto CR, et al. Ritonavir analogous compound useful as retroviral protease inhibitor, preparation of the ritonavir analogous compound and pharmaceutical composition for the ritonavir analogous compound. United States patent 7763733 2010.

10. Max B, Sherer R. Management of the adverse effects of antiretroviral therapy and medication adherence. Clin Infect Dis 2000;2: 96-116.

11. Rodríguez-Spong B, Price CP, Jayasankar A, et al. General principles of polymorphism: a supramolecular perspective. Adv Drug Deliv Rev 2004;56:241-74.

12. Giulietti M, Seckler MM, Derenzo S, et al. Industrial crystallization and precipitation from solutions: state of the technique. Braz J Chem Eng 2001;18:423-40.

13. Azad MA, Knieke C, To D, Davé R. Preparation of concentrated stable fenofibrate suspensions via liquid antisolvent precipitation. Drug Dev Ind Pharm 2014;40:1693-703.

14. Wei L, Ji Y, Gong W, et al. Preparation, physical characterization and pharmacokinetic study of paclitaxel nanocrystals. Drug Dev Ind Pharm 2014. [Epub ahead of print]. doi:10.3109/03639045.2014. 950272.

15. Lindenberg C, Schöll J, Vicum, L, et al. Experimental characterization and multi-scale modeling of mixing in static mixers. Chem Eng Sci 2008;63:4135-49.

16. Lacerda SP. Improvement of dissolution rate of a new antiretrovira drug using an anti-solvent crystallization technology [octoral thesis] Génie des procédés et de l'Environnement, 01-02-2013, INPT.

17. Asthana R, Sobczak N. Wettability, spreading, and interfacial phenomena in high-temperature coatings. J Met Electronic Ed [Online] 2000;52:1-19. Available from: http://www.tms.org/pubs/ journals/JOM/0001/Asthana/Asthana-0001.html [last accessed 24 Jul 2014].

18. Ali HSM, York P, Blagden N. Preparation of hydrocortisone nanosuspension through a bottom-up nanoprecipitation technique using microfluidic reactors. Int J Pharm 2009;375: 107-13.

19. Douroumis D, Fahr A. Nano- and micro-particulate formulations of poorly watersoluble drugs by using a novel optimized technique. Eur J Pharm Biopharm 2006;63:173-5.

20. Thakur RK, Vial C, Nigam KDP, et al. Static mixers in the process industries - a review. Chem Eng Res Des 2003;81:787-826.
21. Vippagunta SR, Wang Z, Hornung S, Krill SL. Factors affecting the formation of eutectic solid dispersions and their dissolution behavior. J Pharm Sci 2007;96:294-304.

22. Wu L, Zhang J, Watanabe W. Physical and chemical stability of drug nanoparticles. Adv Drug Deliv Rev 2011;63:456-69.

23. Thorat AA, Dalvi SV. Liquid antisolvent precipitation and stabilization of nanoparticles of poorly water soluble drugs in aqueous suspensions: recent developments and future perspective. Chem Eng J 2012;181-2:1-34.

24. Pardeike J, Strohmeier DM, Schrödl N, et al. Nanosuspensions as advanced printing ink for accurate dosing of poorly soluble drugs in personalized medicines. Int J Pharm 2011;420:93-100.

25. Shi J. Steric stabilization: literature review: steric stabilization. Ohio State University. Group Inorganic Materials- Literature Review [Online] 2002;1-43. Available from: http://muri.lci.kent.edu/ References/NIM_Papers/stabilization_of_NP_suspensions/2002_ Shi_steric_stabilization.pdf [last accessed 4 Aug 2014].

26. Grahame DC. The electrical double layer and the theory of electrocapillarity. Chem Rev 1947;41:441-501.

27. Laurier LS, Elaine NS, Marangoni DG. Surfactants and their applications. Annu Rep Prog Chem C 2003;99:3-48.

28. Claesson PM, Ninham BW. pH-dependent interactions between adsorbed chitosan layers. Langmuir 1992;8:1406-12.

29. Zhang Z, Le Y, Wang J, et al. Irbesartan drug formulated as nanocomposite particles for the enhancement of the dissolution rate. Particuology 2012;10:462-67.

30. Yue PF, Yuan HL, Yang M, et al. Preparation, characterization, and pharmacokinetic evaluation of puerarin submicron emulsion. PDA J Pharm Sci Technol 2008;62:32-45.

31. Patel VR, Agrawal YK. Nanosuspension: an approach to enhance solubility of drugs. J Adv Pharm Technol Res 2011;2:81-7.

32. Sun Y, Zhu L, Wu T, et al. Stability of amorphous pharmaceutica solids: crystal growth mechanisms and effect of polymer additives. AAPS J 2012;14:380-8

33. Silva R, Ferreira H, Carvalho AC, et al. Protein microspheres as suitable devices for piroxicam release. Colloid Surface B 2012;92: 277-85.

34. Viçosa A, Letourneau J-J, Espitalier F, Ré MI. An innovative antisolvent precipitation process as a promising technique to prepare ultrafine rifampicin particles. J Cryst Growth 2012;342:80-7.

35. Bilati U, Allémann E, Doelker E. Development of a nanoprecipitation method intended for the entrapment of hydrophilic drugs into nanoparticles. Eur J Pharm Sci 2005;24:67-75.

36. Kipp JE. The role of solid nanoparticle technology in the parenteral delivery of poorly water-soluble drugs. Int J Phar 2004;284:109-22.

37. Cho E, Cho W, Cha KH, et al. Enhanced dissolution of megestrol acetate microcrystals prepared by antisolvent precipitation process using hydrophilic additives. Int J Pharm 2010;396:91-8.

38. Salvalaglio M, Vetter T, Giberti F, et al. Uncovering molecular details of urea crystal growth in the presence of additives. J Am Chem Soc 2012;134:17221-33.

39. Lechuga-Ballesteros D, Rodríguez-Hornedo N. The relation between adsorption of additives and crystal growth rate of L-alanine. J Colloid Interf Sci 1993;157:147-53.

40. Takehara A, Fukuzaki S. Effect of the surface charge of stainless steel on adsorption behavior of pectin. Biocontrol Sci 2002;7:9-15. 